\title{
Synthesis of Activated Carbon from Eichhronia Crassipes Plant as Adsorbent for the Removal of Phenol from Aqueous Solution
}

\author{
Hussain Mohammed Ali ${ }^{1,2} *$, Dheaa Zageer ${ }^{1,3}$ and Atheel H. Alwash ${ }^{1}$ \\ ${ }^{1}$ Department of Chemistry, College of Science, Al-Nahrain University, Baghdad-Iraq. \\ ${ }^{2}$ Directorate Water of Karbala, Karbala-Iraq. \\ ${ }^{3}$ Forensic DNA Center for Research and Training, Al-Nahrain University, Baghdad-Iraq. \\ * Corresponding author: hussenmoh77@gmail.com
}

\begin{abstract}
For a friendly environment, adsorbents are prepared from harmful natural sources to reduce their impact on the environment. The preparation of activated carbon from the Eichhornia crassipes was done by carbonization at $450 \mathrm{C}^{\circ}$, followed by activation step at $800 \mathrm{C}^{\circ}$. The adsorption processes were carried out by the batch system to determine the optimal conditions for the removal of phenol from the aqueous solutions. Different parameters were used in batch experiments such as initial concentrations of phenol (in the range from 10-100 ppm), $\mathrm{pH}$ (from 2-12), temperature (from 298-328k), AC dosage (from 0.09-0.4g). All the adsorption experiments were carried out in thermostat shaker at $150 \mathrm{rpm}$. The removal percentage of phenol on activated carbon was $98.2 \%$ at optimum conditions of $10 \mathrm{ppm}$ initial phenol concentration, 25 minutes, $\mathrm{pH}=7,308 \mathrm{k}, 0.2 \mathrm{~g}$ of AC dosage). The thermodynamic functions of phenol adsorption were studied at different temperatures. The values of Gibbs free energy $(\Delta G)$ at maximum removal with temperatures $(298,308,318$ and $328 \mathrm{~K})$ was $(-5.17,-6.83,-8.22,-8.48)$ respectively and enthalpy $\Delta \mathrm{H}$, entropy $\Delta \mathrm{S}$ values was 29.22 and 0.114. The activated carbon extracted from Eichhornia crassipes has a double benefit. first, to remove various organic pollutants such as phenols in aqueous solutions and the second, to create a clean water environment free of this plant found in Iraqi waters.
\end{abstract}

[DOI: 10.22401/ANJS.22.1.07]

Keyword: Adsorption, Phenol, Activated carbon, Eichhornia crassipes.

\section{Introduction}

At the present time and due to increased human activity, the pollution by organic materials became more prevalent than before. Rivers waters face significant challenges due to the discharge of pollutants to them. Sewage water and agricultural and industrial wastewater all contain organic contaminants. There are many methods can be used to remove organic pollutants in the water solutions (i.e., coagulation, flocculation, reverse osmosis, ozone, sedimentation, advanced oxidation, adsorption, ion exchange) [1]. Adsorption on solid adsorbents is one of the most efficient ways to remove organic pollutants from aqueous solutions [2]. Activated carbon (AC) is a strong adsorbent material with a high surface area containing carbon multi-porous that have high adsorption ability [3]. Activated carbon has wide applications in various areas of life [4]. It is used to remove contaminants because of the high surface area it possesses and because it contains pores of an internal micropore type [5]. Activated carbon has been prepared from several organic materials like (sugarcane, coconut husk, pistachio shell, oil palm, bituminous coal, wood, waste, cassava peel, corncob, agricultural, chicken waste, rice husk)[6]. The adsorption method considered as the most simple method that does not give byproducts its materials are stable and constant. which are stable and do not decompose. Cheap and available materials were used for the preparation of activated carbon. It was found that the Eichhornia crassipes plant in the Tigris and Euphrates, where it became a major problem threatening Iraqi waters and its harmful to the environment [7,8]. Adsorption on activated carbon is a very effective way for the removing organic matter, because of the surface area it possesses. The large surface area of activated carbon comes from two methods i.e., physical and chemical method [9]. In the physical method, the raw material is heated in isolation from the air in the range of temperature from $400-500 \mathrm{C}^{\circ}$. The second method is the chemical activation method, which acid or basic material (e g. $\mathrm{KOH}, \mathrm{HCl}$, $\mathrm{ZnCl}_{2}, \mathrm{H}_{2} \mathrm{SO}_{4}, \mathrm{H}_{3} \mathrm{PO}_{4}$ ) is added to the carbon 
followed by heating to $800 \mathrm{C}^{\circ}$ in isolation from air [10]. The aim of this work was to prepare activated carbon from Eichhornia crassipes plant to be used for the removal of phenol from aqueous solution.

\section{Material and method}

\subsection{Activated carbon (AC) from Eichhornia crassipes.}

A sample of the Nile Flower (Eichhornia crassipes) was obtained from a stream branch of the Euphrates River stream in the Husseiniya region of Karbala province in Iraq.

\subsubsection{Preparation of Activated Carbon}

There are two steps for preparation activated carbon as in below.

\section{A-Carbonization.}

The plant was cut into small pieces, then was washed with tap water to remove the clay and the suspended materials. Next, the small pieces are left exposed to air until dry, then the dry pieces were grinded by an electric mill into small pieces. After that, the small pieces were placed in a crucible, inside a muffle furnace free of air, and isolated atmosphere by inert nitrogen gas at $450 \mathrm{C}^{\circ}$ for 2 hours. To complete the process of carbonization, the obtained carbon was taken and crushed using mortar.

\section{B- Chemical Activation}

The carbon was mixed with $0.1 \mathrm{~N}$ hydrochloric acid (1.2 $\mathrm{ml}$ acid to $1 \mathrm{~g}$ carbon) and then was placed in the same isolated muffle furnace at $800 \mathrm{C}^{\circ}$ for 2 hours to activate the carbon. The activated carbon took out from the muffler and left for a while until cools and washed with the much from distilled water. Activated carbon was taken and dried by air followed by an electric oven at $105 \mathrm{C}^{\circ}$ for 3 hours. The activated carbon left out until it reaches room temperature to be ready to use for adsorption experiments [11].

\subsection{Phenol and Chemicals}

Phenol consists of an aromatic ring (aromatic hydrocarbon) and a hydroxyl function of group. It is the simplest molecule of the phenol family it was supplied by Sigma Aldrich with a purity of $99 \%$. These molecules were selected due to its frequency in the residual waters coming from the diverse industries (petrochemical, plastic, pharmaceutical, papermaker, food-processing, etc.). The standard solution of phenol was prepared through dissolve $1 \mathrm{~g}$ of phenol crystals in 1 liter of double distilled water. The other solution was prepared from standard solution by sequential dilution. The present study worked to removal the contaminates from raw water mainly phenolic compound.

\subsection{Characterization Techniques}

There are several tests were performed on activated carbon to study the surface morphology and chemical state using Scanning Electron Microscopy (SEM) (model: Inspects 50FEI company), Energy Dispersive $\mathrm{X}$-ray spectroscopy (EDX), and the chemical bonds were detected by Fourier Transform Infrared (FT-IR) SHIMADZU, (IRPRESTIGE 21). Meanwhile, the particle size and surface of the activated carbon were detected by Rasterizer 2000 and N2 Sorption device, respectively.

\subsection{Adsorption Studies}

Adsorption experiments of phenol on activated carbon were performed by the batch experiments system to obtain optimum conditions for the removal of phenol from aqueous solution. Different initial concentrations of phenol solution were used in the range of 10-100 ppm, pH (2-12), temperature (25-55), and AC dosage (0.09$0.4 \mathrm{~g})$. All the adsorption experiments were carried out with thermostat shaker at $150 \mathrm{rpm}$ and 25-minute contact time. The residual phenol concentration was measured by spectrophotometric (Shimadzu.PC1650 Double beam) at wavelength of $270 \mathrm{~nm}$.

\subsection{Calculations}

The percentage removal of phenol $(\mathrm{R} \%)$ was measured according to Eq.(1) and a measured amount of phenol adsorbed (Qe $\mathrm{mg} / \mathrm{g}$ ) was from Eq. (2) as in below.

$\% R=\left(C i-\frac{C t}{C i}\right) * 100$

$Q e=(C i-C t) * \frac{V}{m}$

$\mathrm{Ci}$ : initial concentration (ppm). $\mathrm{Ct}$ : concentration at any time $(\mathrm{ppm}) . \mathrm{m}=$ Mass of adsorbent $(\mathrm{g}) . \mathrm{V}$ is the volume of phenol solution $(\mathrm{ml})$. The thermodynamic functions can be calculated from equations as in below. 
$\mathrm{kc}=\mathrm{Qe} / \mathrm{Ct}$

$\Delta \mathrm{G}=-\mathrm{RT} \operatorname{lnKC}$

$\ln \mathrm{KC}=\Delta \mathrm{S} / \mathrm{R}-\Delta \mathrm{H} / \mathrm{RT}$

$\mathrm{KC}$ is the equilibrium partition constant, $\mathrm{Qe}$ is the adsorption capacity, $\mathrm{C}_{\mathrm{t}}$ is the concentration at the time, and $\mathrm{R}$ is the gas constant $(8.314 \mathrm{~J}$ $\mathrm{K} / \mathrm{mole}), \mathrm{T}$ is the temperature in Kelvin (k), $\mathrm{Eq}$ (5) called (vant hofe equation) represent a plot of ln $\mathrm{KC}$ vs. 1/T.

\section{Results and Discussion}

\subsection{The particle Size of Adsorbents}

The particles size for AC was measured using Rasterizer 2000 is one of the physical methods to know the nature of the particles size. The test samples were prepared by mixing one spoon from the powder within less than ten milliliters of distilled water and adding some materials for helping maintain the homogeneity of the mixture for a longer period. After adding the powder to the water they are mixed by the spoon to overcome clusters before entering the ultrasonic mixing where it is kept less than 10 minutes after that, a number of droplets are taken and added to the test apparatus provided that the absorption rate is not greater than $20 \%$ where the window of software showed that and the absorption capacity every closer to $20 \%$ as the accuracy increases. The material is then analyzed by the program to obtain the results of the particle size. The particles size to the activated carbon was measured, and the particles size values were between $1.26-632.4 \mu \mathrm{m}$ as in Fig.(1).

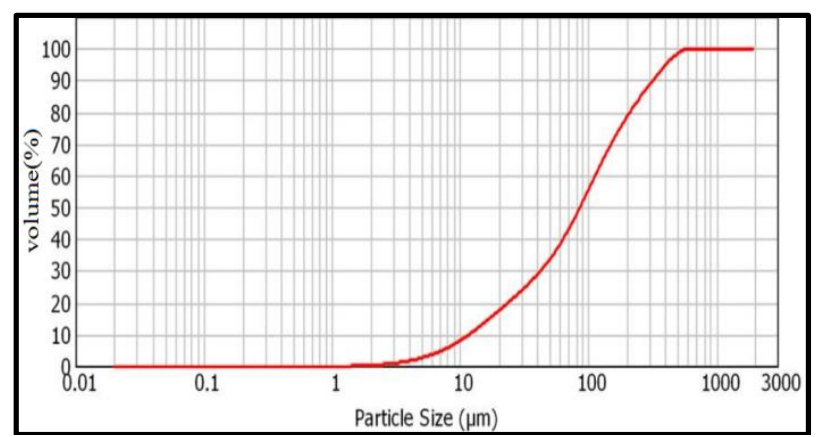

Fig.(1): Particle size of $A C$.

\subsection{The Surface Area of the Adsorbent}

The surface area and porosity of carbons are prominent factors in determining their adsorption capacities [12]. The textural properties of solids are conventionally determined from the adsorption of nitrogen at
$77 \mathrm{~K}$ and the adsorption data are usually analyzed by the application of the BET equation [13]. The surface area of activated carbon was measured by nitrogen adsorptiondesorption (N2 Sorption device) at equilibrium temperature $200 \mathrm{C}^{\circ}$. The measure of AC shows the total surface area value was $360.5 \mathrm{~m} 2 / \mathrm{g}$. This result shows the surface area increases with the present large number of small particle and shows that the increased surface area of activated carbon was compatible with the small particle size values in Fig.(2).

\subsection{Scanning Electron Microscopy}

The magnified images of activated carbon were obtaining using the scanning electron microscopy (SEM). The image shows the particles sizes of activated carbon in the form of small pieces irregular shape containing rough layers in which cavities that increase from the surface area [14] as in Fig.(2).

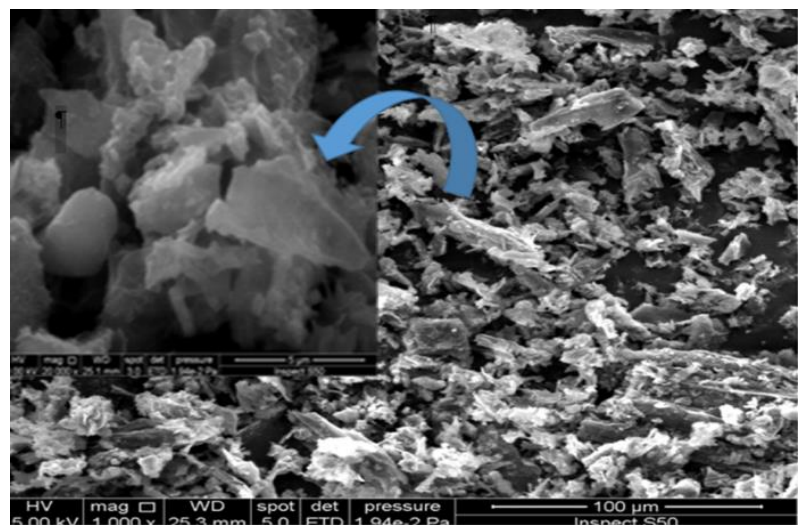

Fig.(2): The image of the activated carbon by Scanning Electron Microscope(SEM).

\subsection{Energy dispersive $x$-ray spectroscopy (EDX).}

Energy dispersive X-Ray analyzer (EDX).an examination that gives quantitative information about the elements of the material, the elements are estimated by X-rays resulting from Exposing the atom to pack of medium power electrons. When the excited atoms relax, they emit rays in the form of photons representing atoms themselves, and these called X-rays[15]. 


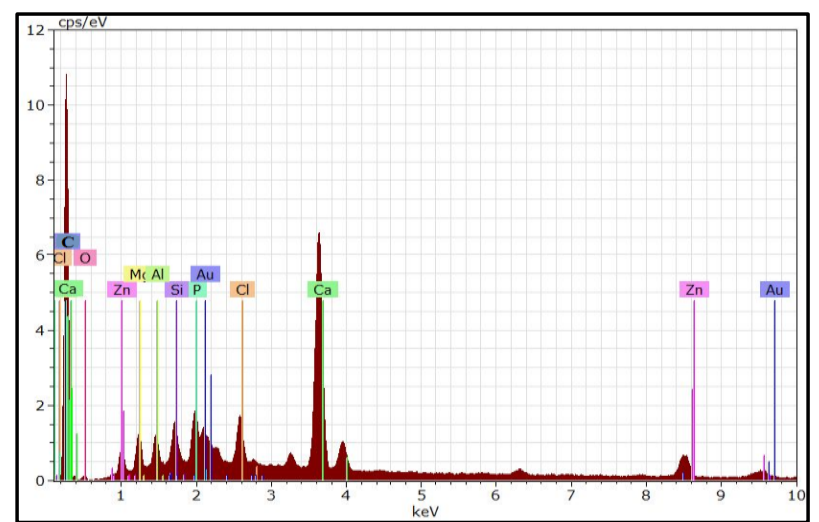

Fig.(3): EDX of the activated carbon.

There are many elements appear from EDX test of the AC adsorbent as in Fig.(3), the main elements percentage of activated carbon was recorded as in Table (1). The highest elements percentage was $66.2 \%$ to the carbon element in the AC.

Table (1)

Elements of activated carbon.

\begin{tabular}{|c|c|}
\hline \multicolumn{2}{|c|}{ EDX of activated carbon } \\
\hline Elements & ratio\% \\
\hline \hline $\mathrm{C}$ & 66.26 \\
\hline $\mathrm{Sb}$ & 13.07 \\
\hline $\mathrm{Ca}$ & 6.07 \\
\hline $\mathrm{W}$ & 3.87 \\
\hline $\mathrm{Pt}$ & 2.22 \\
\hline $\mathrm{Zn}$ & 1.45 \\
\hline $\mathrm{Mg}$ & 1.44 \\
\hline \hline $\mathrm{Cl}$ & 1.38 \\
\hline \hline $\mathrm{P}$ & 1.29 \\
\hline \hline $\mathrm{Si}$ & 1.16 \\
\hline
\end{tabular}

\subsection{Spectrum Analysis by Fourier}

\section{Transform Infrared (FT-IR)}

Fourier Transform Infrared (FT-IR) is an effective analytical method for detecting functional groups and characterizing covalent bonding information. The FTIR analysis appears many spectra of the AC before and after adsorption with phenol as in Fig.(4) and the values in Table (2). The FT-IR analysis of phenol shows characteristic absorption band at 3309, 3087, 1595, 1471, 1364, 1220, 1068, 750 and $687 \mathrm{~cm}^{-1}$ which can be attributed to $\mathrm{O}-\mathrm{H}$ stretching, Ar. $\mathrm{C}-\mathrm{H}$ stretching, $\mathrm{C}=\mathrm{C}$ stretching, $\mathrm{C}-\mathrm{H}$ bending, $\mathrm{C}-\mathrm{O}$ asymmetrical and symmetrical stretching and out of plane bending for mono substituted benzene ring
[16]. While the spectroscopic identification of activated carbon shows bands at 3524, 2973, $1451,1245,1150$ and $869 \mathrm{~cm}-1$ for $\mathrm{O}-\mathrm{H}$ stretching, $\mathrm{C}-\mathrm{H}$ asymmetrical stretching, $\mathrm{C}-\mathrm{H}$ bending, $\mathrm{C}-\mathrm{O}$ asymmetrical stretching, $\mathrm{C}-\mathrm{O}$ symmetrical stretching and $\mathrm{C}-\mathrm{C}$ stretching vibration [17]. All the above spectroscopic data were disappeared when the phenol was mixed with activated carbon this indicating complete the adsorption and bound of all active sites with phenol molecules.

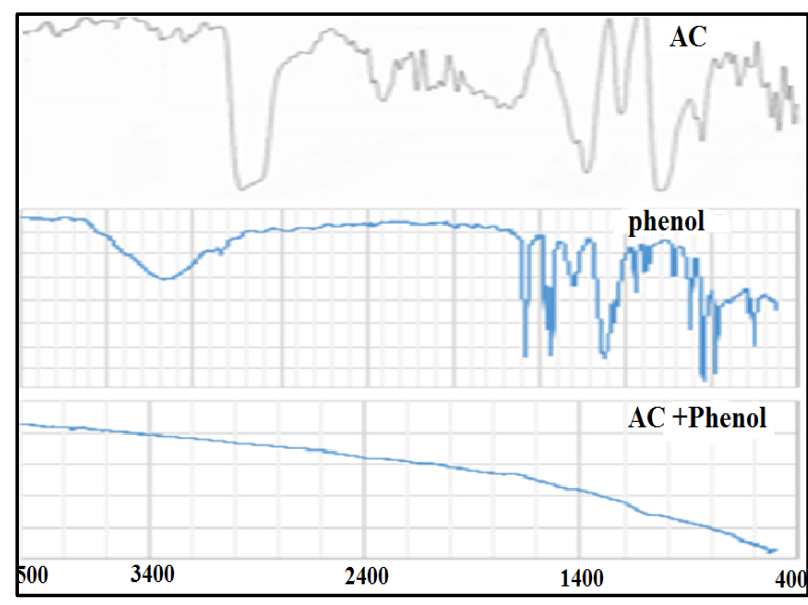

Fig.(4): FTIR spectra of the AC, phenol, and (AC +phenol). 
Table (2)

FTIR values of the AC, phenol and (AC+phenol).

\begin{tabular}{|c|c|c|c|c|c|}
\hline \multicolumn{2}{|c|}{ Activated carbon } & \multicolumn{2}{|c|}{ phenol } & \multicolumn{2}{|c|}{$(\mathrm{AC}+$ phenol $)$} \\
\hline $\begin{array}{l}\text { Bonds } \\
\text { cm }^{-1}\end{array}$ & $\begin{array}{l}\text { Functional } \\
\text { group }\end{array}$ & $\begin{array}{c}\text { Bonds } \\
\text { cm }^{-1}\end{array}$ & $\begin{array}{l}\text { Functional } \\
\text { group }\end{array}$ & $\begin{array}{l}\text { Bonds } \\
\text { cm }^{-1}\end{array}$ & $\begin{array}{l}\text { Functional } \\
\text { group }\end{array}$ \\
\hline 3524 & $\mathrm{O}-\mathrm{Hv}$ & 3309 & $\mathrm{O}-\mathrm{H} v$ & & \\
\hline 2973 & $\mathrm{C}-\mathrm{H}$ asym. $v$ & 3087 & $\mathrm{C}-\mathrm{H}$ Arm. $v$ & & \\
\hline 1451 & $\mathrm{C}-\mathrm{H} \delta$ & 1595 & $\mathrm{C}=\mathrm{Cv}$ & & \\
\hline 1245 & $\mathrm{C}-\mathrm{O}$ asym. $v$ & $\begin{array}{l}1471 \\
1364\end{array}$ & $\mathrm{C}-\mathrm{H} \delta$ & & \\
\hline 1150 & $\overline{\mathrm{C}-\mathrm{O} \text { sym. } v}$ & 1220 & $\mathrm{C}-\mathrm{Ov}$ & & \\
\hline 869 & $\mathrm{C}-\mathrm{Cv}$ & 1068 & $\mathrm{C}-\mathrm{O} \delta$ & & \\
\hline & & $\begin{array}{c}750 \& \\
687\end{array}$ & $\begin{array}{l}\gamma \text { Momo subs. } \\
\text { Benzene ring }\end{array}$ & & \\
\hline
\end{tabular}

4. Determination of the Optimum Conditions of Phenol Adsorption on AC

\subsection{Effect of Contact Time}

The adsorption of phenol was carried out in a batch system with thermostat of shaker $150 \mathrm{rpm}$ at10ppm initial phenol concentration, $0.2 \mathrm{~g}$ of $\mathrm{AC}$ at fixed $\mathrm{pH}=7$. The phenol solution was adjusted by $0.1 \mathrm{M}$ of $\mathrm{NaOH}$ or $\mathrm{HCl}$ solution. Different contact time were studied (i.e. 1,3,5,10,15,25 and 30 minutes) with the number replicates was 3. Fig.(5) shows the maximum percentage of removal of phenol was $98.2 \%$ at 25 minutes. At the beginning of the reaction, the removal percentage increased, due to the number of active sites on the activated carbon was large and gradually the reaction becomes slowly because the number of active sites was decreased with increasing the contact time until reached maximum removal [18]. The 25 minutes was the optimal contact time.

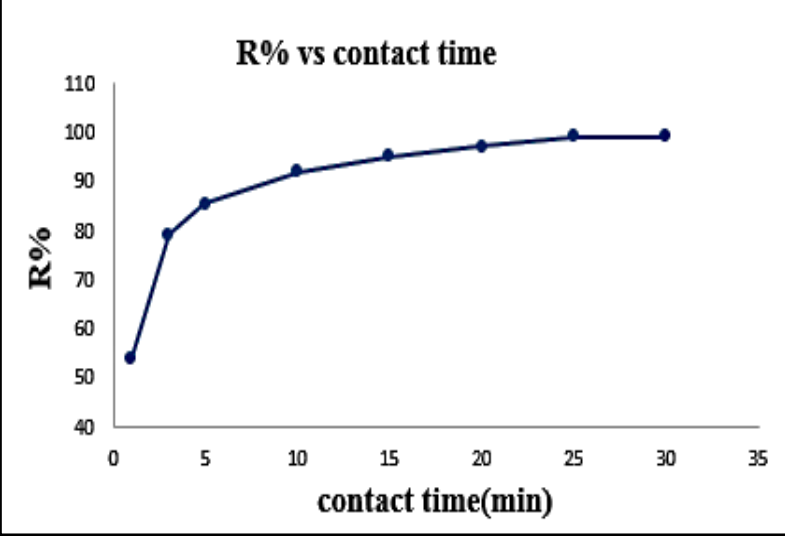

Fig.(5): R\% of phenol on (AC) with the contact time.

\subsection{Effect of $\mathrm{pH}$ on Adsorption Process}

The effect of $\mathrm{pH}$ on adsorption of phenol on the activated carbon was studied at initial phenol concentration of $10 \mathrm{ppm}$ with $0.2 \mathrm{~g}$ of $\mathrm{AC}$ as an adsorbent with different $\mathrm{pH}$ values $(2,4,7,9$ and 12) at fixed (temperature, contact time) respectively. The adsorption process was carried out in a batch system with thermostat of shaker150 rpm. Fig.(6) shows the percentage removal $(\mathrm{R} \%)$ of phenol increased at $\mathrm{pH}$ value (from 2 to 7 ), after the $\mathrm{pH}=7$ the percentage removal was decreased sharply to $75.7 \%$ at $\mathrm{pH}=12$. The pka value of phenol is 9.89 thus, phenol has a negative charge in case of $\mathrm{pH}>7$. When the $\mathrm{pH}>\mathrm{pH} \mathrm{PZC}=9.7$, the surface of activated carbon has a negative charge, in this case, the electrostatic repulsion increase that led decrease in the adsorption process.

However, at lower $\mathrm{pH}$ (2 and 4). When the $\mathrm{pH}<\mathrm{pHPZC}=9.7$ the $\mathrm{H}+$ ion will competing with the phenol onto adsorption sites on the surface of AC that leading decrease in the adsorption process [19] Fig.(7) shows the maximum percentage removal at $\mathrm{pH}=7$ and $\mathrm{pH}=4$ was $(98.2 \%, 98.8 \%)$ respectively. In this study, the removal of organic pollutants from water solutions, which can be applied to drinking water treatment plants. Therefore, according to the standard of drinking water, the $\mathrm{pH}$ values are required (from 6.5 to 8.5) [20]. So consider the $\mathrm{pH}=7$ value is ideal for use, and it is close to the highest percentage removal value at $\mathrm{pH}=4$. 


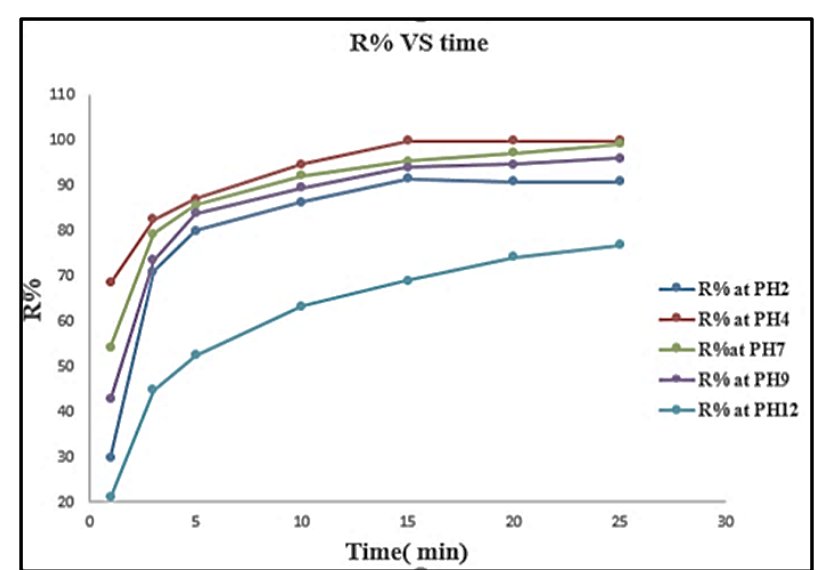

Fig.(6): R\% of phenol for different pH at $25 C^{o}$.

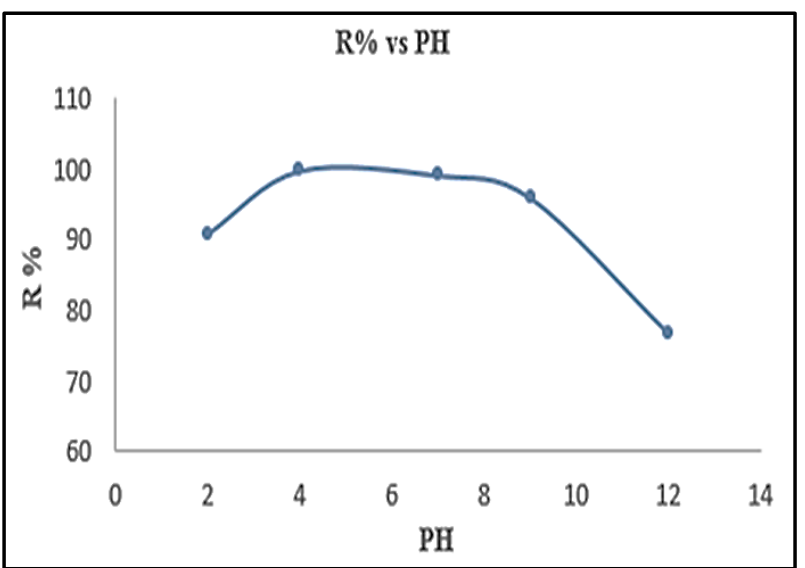

Fig.(7): Maximum R\% for 25 min at $25 C^{o}$.

\subsection{Effect of Temperature on Adsorption Process}

The effect of temperature on adsorption of phenol with activated carbon was carried out in a batch system with thermostat shaker, at initial phenol concentration at $10 \mathrm{ppm}$ with constant contact time at $25 \mathrm{~min}$ and $\mathrm{pH}=7$. Different temperatures were used to estimate the effect of temperature on the adsorption process (i.e.298, 308, 318 and $328 \mathrm{k}$ ). The result in Figure8 show the percentage of removal increased with an increase in temperature. The suggested reason is that when the temperature increases, the kinetic energy of the phenol molecules increases, giving a stronger impetus to the entry of these molecules into the small pores in the activated carbon structure, this interpretation was according to previous studies in terms of the effect the temperatures on the phenol adsorption using activated carbon [21,22]. Several studies have also shown that phenol adsorption on the surface of activated carbon decreases with increasing temperature because of break the bonds at the high temperatures [23]. The maximum removal efficiency of phenol was $98.8 \%$ at $328 \mathrm{~K}$ and this result nearby to removal efficiency $98.2 \%$ at $308 \mathrm{k}$. Therefore, the temperature at $308 \mathrm{k}$ value is considered optimal to use.

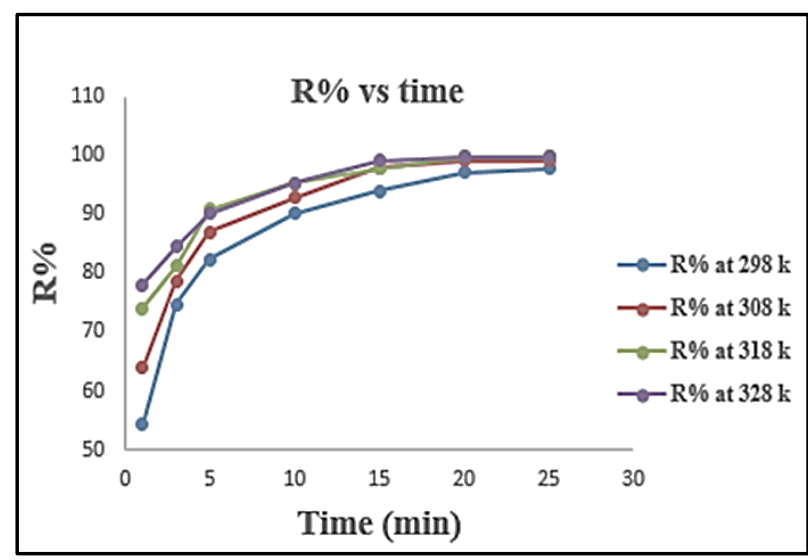

Fig.(8): R\% values with different temperature.

\subsection{Effect of Initial Concentrations on the Adsorption Process}

The effect of a different initial concentration of phenol on the adsorption process with $0.2 \mathrm{~g}$ of activated carbon was studied at 10, 20, 40, 60, 80, and $100 \mathrm{ppm}$ with a fixed temperature of $308 \mathrm{~K}$, contact time of $25 \mathrm{~min}$ and $\mathrm{pH}=7$. The adsorption process was carried out in a batch system with thermostat of shaker $150 \mathrm{rpm}$. Fig.( $(9$ shows the percentage of removal of phenol at different initial concentration. The results detect a decrease in removal percentage with increasing of initial concentration of phenol solution. This could be ascribed that in an early stage the number of vacant sites and a functional groups on the activated carbon was large and available for adsorption of phenol molecules and an increase of phenol uptake dependent on the mass driving force[24]. This force has little resistance and allows to the solutes to pass through pores on the adsorbent and gradually the number of vacant sites decreases with increasing concentration of phenol solution, thus led decrease in the R\% after contact time (25min). The lower $\mathrm{R} \%$ was $76.2 \%$ at an initial concentration of phenol $100 \mathrm{ppm}$, and the maximum $\mathrm{R} \%$ was $98.2 \%$ at initial phenol concentration of $10 \mathrm{ppm}$ therefore, this value as the optimum value in this study. 


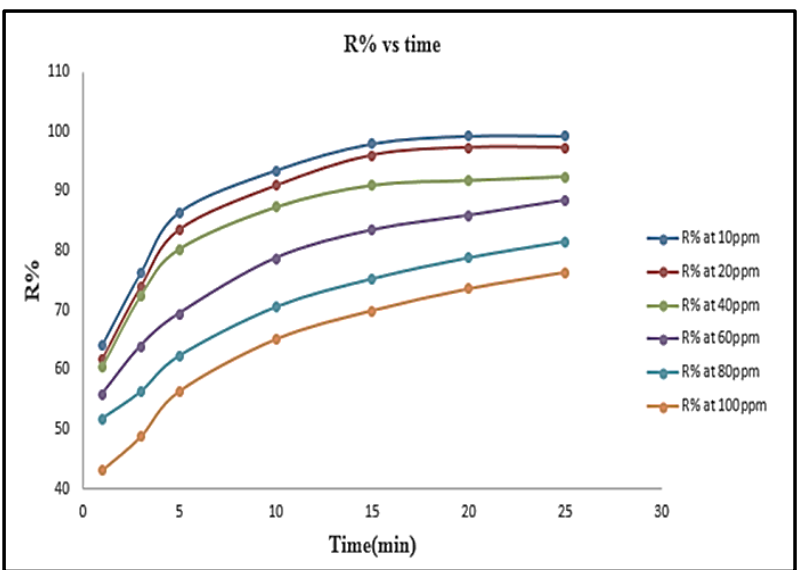

Fig.(9): R\% at a different initial concentration of phenol solution.

\subsection{Effect of Adsorbents Dosage on the Adsorption Process}

Effect of adsorbents dosage on the adsorption process of phenol using the activated carbon was studied in a batch system with thermostat of shaker $150 \mathrm{rpm}$. The initial phenol concentration was $10 \mathrm{ppm}$, with different dosage of activated carbon (i.e. 0.09, $0.1,0.2,0.3$, and $0.4 \mathrm{~g}$ ) and fixed temperature of $308 \mathrm{~K}$, contact time $25 \mathrm{mint}, \mathrm{pH}=7$. Fig.(10) shows the maximum removal\% of phenol was $98.8 \%$ at $0.4 \mathrm{~g}$ of $\mathrm{AC}$, however, the percentage removal was $98.2 \%$ at $(0.2$ and $0.3 \mathrm{~g})$ and these values consider the best economic result. Generally, from batch experiments, the adsorption process increase gradually with increasing the dosage of adsorbent because the surface area increases with the increasing amount of AC dosage. Farther more, the number of active sites on $\mathrm{AC}$ and the ion transfer sites increase[25]. These factors led to increasing adsorption process and removal percentage. The results show the $0.2 \mathrm{~g}$ value is considered as the optimal.

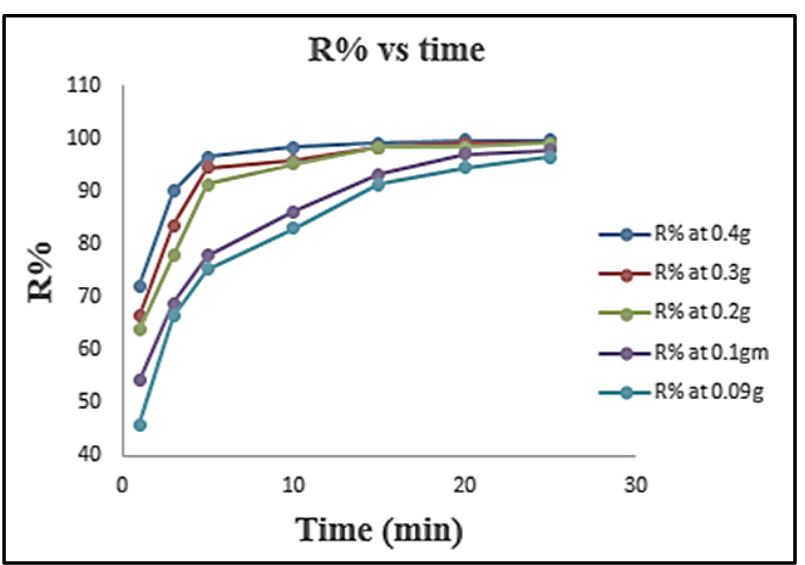

Fig.(10): $R \%$ values for different $(A C)$ dosage at 25 min.

\subsection{Thermodynamic Studies of phenol Adsorption}

The thermodynamic parameters were studied during the adsorption experiments of phenol on activated carbon with different temperatures and at $\mathrm{pH}=7$. The thermodynamic parameters can be calculated from maximum values at $208 \mathrm{~K}$ using equations 3,4 and 5 . When $\Delta \mathrm{G}$ values were negative means the reaction was spontaneous. Other parameters such as $(\Delta \mathrm{H}$ and $\Delta \mathrm{S})$ was calculated using the values in Table (3) with Eq 5 (Van' t Hoff equation). Fig.(11) shows the slope and intercept from the plot of $\ln \mathrm{k}$ versus $1 / T$. the value of $\Delta G$ in between 0 and $20 \mathrm{kj} / \mathrm{mole}$ that means the reaction is electrostatic interaction (physical adsorption), while the value of $\Delta \mathrm{G}$ is more negative ranging from -80 to $-400 \mathrm{~kJ} / \mathrm{mole}$ that means the adsorption involves charge sharing (chemisorption) [26]. The values of $\Delta \mathrm{H}$ and $\Delta \mathrm{S}$ shows positive values, therefore, the reaction is endothermic and has (disorder), and the interaction between phenol and active sites on the surface of AC show the adsorption-type was the electrostatic (physical adsorption). 
Table (3)

Thermodynamics Parameters for Adsorption of phenol on AC at pH=7.

\begin{tabular}{|c|c|c|c||c||c|c||c||c||c||}
\hline $\begin{array}{c}\mathbf{C t} \\
\mathbf{p p m}\end{array}$ & $\begin{array}{c}\mathbf{Q e} \\
\mathbf{M g} / \mathbf{g}\end{array}$ & $\mathbf{K C}$ & $\begin{array}{c}\mathbf{L n} \\
\mathbf{K C}\end{array}$ & $\begin{array}{c}\mathbf{T} \\
\left(\mathbf{C}^{\mathbf{0}}\right)\end{array}$ & $\begin{array}{c}\mathbf{T} \\
\mathbf{( K )}\end{array}$ & $\mathbf{1 / T} \mathbf{K})$ & $\begin{array}{c}\Delta \mathbf{G} \\
\mathbf{K J} / \mathbf{m o l}\end{array}$ & $\begin{array}{c}\Delta \mathbf{H} \\
\mathbf{K J} / \mathbf{m o l}\end{array}$ & $\begin{array}{c}\Delta \mathbf{S} \\
\mathbf{K J} / \mathbf{m o l}\end{array}$ \\
\hline $\mathbf{0 . 3}$ & 2.42 & 8.066 & 2.08 & 25 & 298 & 0.0033 & -5.17 & & \\
\hline $\mathbf{0 . 1 7}$ & 2.45 & 14.411 & 2.66 & 35 & 308 & 0.0032 & -6.83 & \multirow{2}{*}{29.22} & \multirow{2}{*}{0.114} \\
\hline $\mathbf{0 . 1 1}$ & 2.47 & 22.454 & 3.11 & 45 & 318 & 0.0031 & -8.22 & & \\
\hline $\mathbf{0 . 1 1}$ & 2.47 & 22.454 & 3.11 & 55 & 328 & 0.003 & -8.48 & & \\
\hline
\end{tabular}

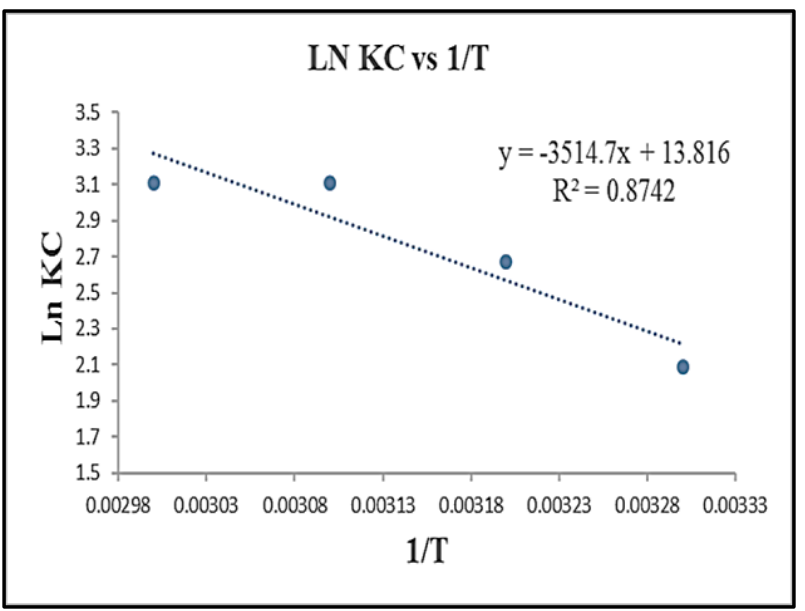

Fig.(11): The Van't Hoff Plot for Adsorption of phenol on $\mathrm{AC}$ at $\mathrm{pH}=7$.

\section{Conclusion}

The Eichhornia crassipes plant use for the preparation activated carbon at two steps. The first step is carbonization at $450 \mathrm{C}^{\circ}$ and the second step is the activation at $800 \mathrm{C}^{\circ}$. The adsorption processes were carried out by the batch experiments system to determine the optimal conditions for the removal of phenol from the aqueous solutions. Different parameters were used in batch experiments such as initial concentrations of phenol (from 10-100 ppm), $\mathrm{pH}$ (from 2-12), temperature (from 25-55 K), AC dosage (from 0.09-0.4g). The conditions of improvement were determined by removal of phenol from aqueous solutions by activated carbon and the highest removal percentage was $98.2 \%$ under these conditions (10 ppm initial conc.,25 minutes, $\mathrm{pH}=7,308 \mathrm{k}, 0.2 \mathrm{~g}$ of $\mathrm{AC}$ dosage). The thermodynamic functions of adsorption reactions were calculated at different temperatures. The results showed that the adsorption process was spontaneous due to the negative value of the free energy $(\Delta G)$ and the reaction was endothermic and it has kinetic energy (randomness) due to the positive values of $(\Delta \mathrm{H}, \Delta \mathrm{S})$. Eichhornia crassipes possesses a double benefit and proved high efficiency to phenol removal from aqueous solutions and at the same time, harmful plants in the aquatic environment can be eliminated.

\section{Acknowledgment}

Thanks and appreciation to the Chemistry Department the College of the Science of AlNahrain University for cooperation and providing all required materials.

\section{Reference}

[1] Akl M. A., Dawy MB., Serage AA., Analytical \& Bioanalytical Techniques Efficient Removal of Phenol from Water Samples Using Sugarcane Bagasse Based Activated Carbon, 5(2), 55-67, 2014.

[2] Navarro AE., Cuizano NA., Lazo JC., SunKou MR., Llanos BP., Comparative study of the removal of phenolic compounds by biological and non-biological adsorbents, J Hazard Mater., 164(2), 1439-1446, 2009.

[3] Chen Y., Zhu Y., Wang Z.,Application studies of activated carbon derived from rice husks produced by chemical-thermal process-A review, Adv Colloid Interface Sci.,163(1), 39-52, 2011.

[4] Chen C., Zhao P., Huang Y., Tong Z., Li Z., Preparation and Characterization of Activated Carbon from Eucalyptus Sawdust I. Activated by $\mathrm{NaOH}$, J Inorg Organomet Polym Mater., 23(5), 1201-1209, 2013.

[5] Dias J. M., Alvim-ferraz MCM., Almeida M. F., Waste materials for activated carbon preparation and its use in aqueous-phase treatment: A review, 85, 833-846, 2007.

[6] Binanipuram P., Kerala O., Preparation and characterization of activated carbon, 5, 551-558, 2016.

[7] Thapa G., Das D., Gunupuru LR., Tang B., Endurance assessment of Eichhornia crassipes (Mart.) Solms, in heavy metal- 
contaminated site-A case study"., Cogent Environ Sci., 2(2), 34-39, 2016.

[8] Sebiawu G., Mensah N., Mensah F., "Analysis of Heavy Metals Content of Tobacco and Cigarettes sold in Wa Municipality of Upper West Region, Ghana". Chemical and Process Engineering Research, 25, 24-34, 2014.

[9] Baseri J. R., Palanisamy P. N., Sivakumar P., Preparation and characterization of activated carbon from Thevetia peruviana for the removal of dyes from textile waste water"., Adv Appl Sci Res, 3(1), 377-383, 2012.

[10] Ademiluyi F. T., Amadi S. A., Amakama N. J. Adsorption and Treatment of Organic Contaminants using Activated Carbon from Waste Nigerian Bamboo, J Appl Sci Environ Manag.,13(3), 39-47, 2009.

[11] Singh R. K., Utilization of Waste Tire Char and its Applications in Liquid Phase Adsorption: A review II, Experimental methods for carbon production from tires .,1-5, 2014.

[12] Akl M. A., Atta A., Youssef AEM., Ibraheim M. A., The Utility of Novel Superabsorbent Core Shell Magnetic Nanocomposites for Efficient Removal of Basic Dyes from Aqueous Solutions, J Chromat Sep Tech., 4(185), 2-12, 2013.

[13] Salame I. I., Bagreev A., Bandosz T. J., Revisiting the effect of surface chemistry on adsorption of water on activated carbons, J Phys Chem B.,103(19), 3877-3884, 1999.

[14] Baseri J. R., Palanisamy P. N., Sivakumar P., Preparation and characterization of activated carbon from Thevetia peruviana for the removal of dyes from textile waste water, Adv Appl Sci Res., 3(1), 377-383., 2012.

[15] Bell D. C., Garratt-Reed A. J., Energy Dispersive X-Ray Analysis in the Electron Microscope, Garland Science; 2003.

[16] Silverstein R. M., Francis X. Webster., David J. Kiemle DLB., Spectrometric Identification of Organic Compounds, Wiley., 2015.

[17] Naeem S., Baheti V., Militky J., Removal of textile dye methylene blue from liquid-phase by activated carbon from Aloe Vera wastes, Int J Eng Tech Res., 9(1), 1-8, 2016.
[18] Farhan AM., Sameen A. S., Kinetic study of adsorption rhodamine $6 \mathrm{G}$ dye from aqueous solutions using bentonite clay, Am J Environ Eng., 4(1), 11-17, 2014.

[19] Ma Y, Gao N., Chu W., Li C., Removal of phenol by powdered activated carbon adsorption 2013.

[20] Quality standards for water pollution. environmental WQS.pdf. 2015. https://www.env.go.jp/en/water/wq/wp.pdf.

[21] Banat F., Al- Asheh S., Al- Makhadmeh L., Utilization of raw and activated date pits for the removal of phenol from aqueous solutions, Chem Eng Technol Ind Chem Equipment- Process Eng., 27(1), 80-86, 2004.

[22] Srivastava VC., Swamy MM., Mall ID., Prasad B., Mishra I. M., Adsorptive removal of phenol by bagasse fly ash and activated carbon: Equilibrium, kinetics and thermodynamics, Colloids Surfaces A Physicochem Eng Asp., 272(1-2), 89-104, 2006.

[23] Andriantsiferana C., Delmas H., Mohamed E. F., Removal of organic compounds from water by adsorption and photocatalytic oxidation, Sci Prod, 2011.

[24] Hansdah B., Adsorption of methylene blue and phenol on activated carbon prepared from Fox Nutshell by $\mathrm{K}_{2} \mathrm{CO}_{3}$ activator 2016.

[25] Tumin ND., Chuah AL., Zawani Z., Rashid S. A.,Adsorption of copper from aqueous solution by Elais Guineensis kernel activated carbon, J Eng Sci Technol., 3(2), 180-189, 2008.

[26] Singh D., Studies of the adsorption thermodynamics of oxamyl on fly ash, Adsorpt Sci Technol.,18(8), 741-748, 2000. 